\title{
Structure, morphology, and mechanical properties of polysiloxane elastomer composites prepared by in situ polymerization of zinc dimethacrylate
}

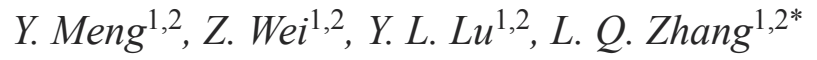 \\ ${ }^{1}$ Key Laboratory of Beijing City for Preparation and Processing of Novel Polymer Materials, Beijing University of \\ Chemical Technology, 100029 Beijing, PR China \\ ${ }^{2}$ State Key Laboratory of Organic-Inorganic Composites, Beijing University of Chemical Technology, 100029 Beijing, \\ PR China
}

Received 18 March 2012; accepted in revised form 24 May 2012

\begin{abstract}
Methyl vinyl silicone rubber/zinc dimethacrylate (VMQ/ZDMA) composites were prepared through in situ polymerization of ZDMA monomers during the peroxide curing. The polymerization conversion of ZDMA and morphology of the VMQ/ZDMA composites were studied. The results showed that most of the ZDMA monomers participated in the in situ polymerization during the cross-linking of the VMQ matrix and uniform nanophases were formed in the composites. The 'dissolving-diffusion' model was used to explain the micro-nano transformation of ZDMA. According to the model, a uniform nano-dispersed structure could be obtained through the in situ reaction even though the initial dispersion of ZDMA in the blends was poor. In addition, tensile tests of VMQ/ZDMA composites showed that ZDMA had a significant reinforcement on the mechanical properties of VMQ, and the best mechanical properties were obtained when the amounts of peroxide and ZDMA were 5 and $40 \mathrm{phr}$, respectively. The gross crosslink density and ionic crosslink density increased as the amount of ZDMA increased, but the covalent crosslink density decreased slightly. These results indicated that the ionic crosslink structure had a significant effect on the mechanical properties of VMQ/ZDMA composites.
\end{abstract}

Keywords: nanocomposites, reinforcements, silicone rubber, zinc dimethacrylate

\section{Introduction}

Because of its unique chemical structure, silicone rubber exhibits a list of excellent properties including a large degree of flexibility, climate and oxidation resistance, thermal stability, low electrical conductivity, biocompatibility, low surface tension, and high permeability $[1,2]$. As a result of these excellent properties, silicone rubber is widely used in aerospace industry, automobile industry, electronic industry and biomedical applications [2-5]. However, silicone rubber has low mechanical strength because of the weak intermolecular forces between polymer chains [6], and the weak mechanical prop- erties seriously limit the practical application of silicone rubber [7]. Therefore, improving the mechanical properties of silicone rubber is of foremost importance. At present, fumed or precipitated silica is most commonly used to reinforce silicone rubber; other fillers like clays, graphite, carbon nanotubes, and polyhedral oligomeric silsesquioxanes have also been reported to be effective reinforcing agents [8-12]. However, it is very difficult for nano-sized particles to disperse in a polymer matrix with low viscoelasticity, and a long mixing time and high dispersion energy are required to obtain fine dispersion. Hence, it is meaningful to find new methods

\footnotetext{
${ }^{*}$ Corresponding author, e-mail: zhanglq@mail.buct.edu.cn
}

(c) BME-PT 
and reinforcing agents with good processability, fine dispersion, and high reinforcing effect to improve the mechanical properties of silicone rubber. The 'in situ reaction' technique is an effective method to obtain fine dispersion of fillers in a polymer matrix. Generally, two 'in situ reaction' methods can be used for the preparation of rubber composites: the 'sol-gel' method and the 'in situ polymerization' method. An example of the 'sol-gel' method is the 'sol-gel' hydrolysis of alkoxysilanes (organosilicates) to form silica in situ within a polymer matrix [13-17]. Ning et al. [15] carried out many studies on reinforcing polydimethylsiloxane by the in situ precipitation of silica, and found that the generated particles were dispersed at the nano-level and considerable reinforcement of the elastomer could be achieved. Other particles generated in situ, for example, titania, have been also reported to have a good reinforcement on elastomers $[16,17]$. However, the cost of this method is higher than that of conventional 'ex situ' methods [8]. In the 'in situ polymerization' method, reactive monomers are polymerized to generate reinforcing particles. Among the reactive monomers, metal salts of unsaturated carboxylic acids are the typical monomers widely used to improve the properties of elastomers [18-24, 2632]. Wen et al. [21] synthesized particles of acrylato(1,10-phenanthroline)bis (2-thenoytrifluoroacetonato) samarium [Sm(TTA)2-(AA)(Phen)], which combined the good fluorescence property of Sm(TTA)3(Phen) and the reactivity of acrylic acid with radicals, and used the particles to prepared HNBR/Sm(TTA)2-(AA)(Phen) composites. It was suggested that a fine dispersion of the particles in HNBR was obtained due to the in situ reaction. Lu et al. [22, 23] added zinc dimethacrylate (ZDMA) into different kinds of elastomers and found that uniform nanophases were formed by the in situ polymerization of ZDMA and the mechanical properties of the resulting composites were significantly improved. The 'in situ polymerization' method is relatively simpler and less expensive than the 'solgel' method, and its reinforcing effect is more remarkable.

In this study, we attempted to improve the properties of methyl vinyl silicone rubber (VMQ) by the 'in situ reaction' method. We selected ZDMA as the reinforcing agent because ZDMA shows better reinforcement than most of other metal salts of unsaturated carboxylic acids do [26]. VMQ/ZDMA composites with different amounts of peroxide and ZDMA were prepared, and the polymerization conversion of ZDMA, the morphology and the crosslink structure of these VMQ/ZDMA composites were studied. The effect of peroxide content and ZDMA content on the mechanical properties of the VMQ/ ZDMA composites was also investigated.

\section{Experimental \\ 2.1. Materials}

VMQ having $0.15 \%$ vinyl substituent and a molecular weight of $550000 \mathrm{~g} / \mathrm{mol}$ was obtained from Chenguang Chemical Research Insititute, Sichuan, China. Zinc Dimethacrylate (ZDMA) (grade Saret 634) was purchased from Sartomer Co., USA. The peroxide used was 2,5-bis(tert-butylperoxy)-2,5dimethyl hexane (DBPMH), which was purchased from Akzo Nobel Cross-Linking Peroxide Co., Ltd., Ningbo, China.

\subsection{Preparation of $V M Q / Z D M A$ composites}

At room temperature, silicone rubber and ZDMA were mixed on a two-roll mill for 15 minutes, followed by the addition of DBPMH. The resulting blends were cured at $160^{\circ} \mathrm{C}$ in an electrically heated hydraulic press for their respective optimal cure time $\left(t_{90}\right)$ obtained from the curing curve.

The ZDMA/DBPMH blend was prepared as follows: (1) the ZDMA and DBPMH (ZDMA/DBPMH $6: 1$, weight ratio) were dispersed in acetone to obtain a turbid liquid (DBPMH can dissolve in acetone but ZDMA can't); (2) after being stirred for 24 hours at room temperature, the prepared turbid liquid was dried at $60^{\circ} \mathrm{C}$ to remove acetone, and then the ZDMA/DBPMH blend was obtained.

\subsection{Measurements}

\subsubsection{Curing characteristics of VMQ blends}

Curing characterisitics of VMQ blends were determined with an oscillating disc rheometer (M2000FA) made by Gotech Testing Machines (Dong Guan) Co. LTD. The curing dynamics of the rubbers were characterized at $160^{\circ} \mathrm{C}$ with an angular displacement of $0.5^{\circ}$. 


\subsubsection{Fourier transform infrared spectroscopy (FTIR)}

FTIR analysis was performed on an FTIR spectrometer (Tensor 27, Bruker Optik Gmbh Co., Germany). The scan range was 4000 to $600 \mathrm{~cm}^{-1}$ with a resolution of $4 \mathrm{~cm}^{-1}$.

\subsubsection{X-ray diffraction (XRD)}

$\mathrm{X}$-ray diffraction (XRD) analysis was carried out on a Rigaku D/Max 2500 X-ray diffractometer (Rigaku Inc., Sendagaya, Japan) with $\mathrm{Cu} \mathrm{K} \alpha$ radiation (at $40 \mathrm{kV}$ and $100 \mathrm{~mA}$ ). The scanning was performed in the diffraction angle (20) range from 3 to $40^{\circ}$ at a rate of $5^{\circ} / \mathrm{min}$.

\subsubsection{Scanning electron microscopy (SEM)}

Scanning electron microscopy observations were performed on an S4700 field emission scanning electron microscope (Hitachi Co., Japan) at a voltage of $20 \mathrm{kV}$.

\subsubsection{Polarizing optical microscopy (POM)}

The VMQ/ZDMA blends before vulcanization were difficult to observe on a scanning electron microscope or transmission electron microscope because they were very viscous fluids. Instead, the VMQ/ ZDMA blends were observed on a polarizing optical microscope (ZEISS Axioskop 40A, Germany). In this technique, the samples were heated to $160^{\circ} \mathrm{C}$ on a hot-stage, and the morphology change during the peroxide curing was recorded.

\subsubsection{Transmission electron microscopy (TEM) and high resolution transmission electron microscopy (HRTEM)}

Both transmission electron microscopy (TEM) and high resolution transmission electron microscopy (HRTEM) were performed to observe the morphology of VMQ/ZDMA composites. TEM was carried out on an H-800-1 transmission electron microscope (Hitachi Co., Japan) and HRTEM was carried out on a JEM-3010 transmission electron microscope (Hitachi Co., Japan). The thin sections for TEM and HRTEM experiments were cut by a microtome at $-100^{\circ} \mathrm{C}$ and collected on cooper grids.

\subsubsection{Differential scanning calorimetry (DSC)}

DSC measurements were carried out on STARE system DSC 1 instrument (Mettler-Toledo Interna- tional Inc., Switzerland). The sample was heated from 30 to $350^{\circ} \mathrm{C}$ under nitrogen atmosphere with the heating rate of $10^{\circ} \mathrm{C} / \mathrm{min}$. For isothermal DSC analysis, the sample were heated to $160^{\circ} \mathrm{C}$ rapidly and kept at $160^{\circ} \mathrm{C}$ for 20 minutes.

\subsubsection{Mechanical properties}

Tensile tests were performed on a CTM 4104 tensile tester (SANS, Shenzhen, China) at a cross-head speed of $500 \mathrm{~mm} / \mathrm{min}$ and a temperature of $25 \pm 2^{\circ} \mathrm{C}$ according to Chinese Standards GB/T528-1998 and GB/T529-1999.

\subsubsection{Measurements of crosslink density}

The crosslink density was determined by equilibrium swelling. A certain amount of samples (about $0.15 \mathrm{~g}$ ) was swollen in toluene in a sealed vessel at $25 \pm 0.2^{\circ} \mathrm{C}$ for 5 days. Then the samples were taken out and immediately weighed on an analytical balance after the surface toluene was blotted off with tissue paper. Subsequently, the samples were dried in a vacuum oven at $80^{\circ} \mathrm{C}$ for one day to remove all the solvent and weighed again. The crosslink density of the samples $\left(v_{\mathrm{e}}\right)$ was calculated by the FloryRehner equation (Equation (1)) [25]:

$\nu_{\mathrm{e}}=\frac{\ln \left(1-v_{2}\right)+v_{2}+\chi v_{2}}{V_{0}\left(v_{2}^{1 / 3}-\frac{v_{2}}{2}\right)}$

where $V_{0}$ is the molar volume of the solvent ( $106.54 \mathrm{~cm} / \mathrm{mol}$ for toluene), $\chi$ is the interaction parameter of VMQ and toluene and is taken as 0.465 here [6], and $v_{2}$ is the volume fraction of the polymer in the vulcanizate swollen to equilibrium. The parameter $v_{2}$ was calculated by Equation (2):

$$
v_{2}=\frac{\frac{m_{0} \phi(1-\alpha)}{\rho_{2}}}{\frac{m_{0} \phi(1-\alpha)}{\rho_{2}}+\frac{m_{1}-m_{2}}{\rho_{1}}}
$$

where $m_{0}, m_{1}$ and $m_{2}$ are the masses of original sample, sample swollen to equilibrium, and dried sample, respectively, $\phi$ is the mass fraction of VMQ in the original sample, $\rho_{1}$ and $\rho_{2}$ are the density of toluene and density of gum VMQ vulcanizate, respectively, and $\alpha$ is the mass loss of gum VMQ vulcanizate during swelling.

For the measurements of covalent crosslink density, samples (about $0.5 \mathrm{~mm}$ in thickness) were swollen 
in a mixture of dilute hydrochloric acid $(1 \mathrm{~mol} / \mathrm{L})$ and acetone (the volume ratio of dilute hydrochloric acid and acetone is 1:9) for 2 days to destroy the ionic network, and then placed for 3 days in a Soxhlet extractor containing acetone, and vacuum dried. The crosslink density of samples before acidolysis $\left(v_{\mathrm{e}}\right)$ and the crosslink density of samples after acidolysis $\left(v_{\mathrm{e} 1}\right)$ present the gross crosslink density and the covalent crosslink density, respectively, and the ionic crosslink density $\left(v_{\mathrm{e} 2}\right)$ was calculated by subtracting vel from $v_{\mathrm{e}}$.

\section{Results and discussion}

\subsection{Polymerization conversion of ZDMA}

To verify the in situ reaction of ZDMA in VMQ matrix during the peroxide curing, transmission FTIR spectroscopy was performed. The FTIR spectra of ZDMA, ZDMA after heat treatment at $160^{\circ} \mathrm{C}$ for $15 \mathrm{~min}$ (the optimum curing time $t_{90}$ of the blend), ZDMA/DBPMH blend, ZDMA/DBPMH blend after heat treatment at $160^{\circ} \mathrm{C}$ for $15 \mathrm{~min}$, $\mathrm{VMQ} / Z D M A$ blend, and VMQ/ZDMA composite are shown in Figure 1. In the spectrum of ZDMA (Figure 1 curve a), the bands at 1560 and $1420 \mathrm{~cm}^{-1}$ are attributed to the symmetrical and anti-symmetrical vibrations of $\mathrm{COO}-$; the band at $1651 \mathrm{~cm}^{-1}$ is assigned to the stretching vibration of $\mathrm{C}=\mathrm{C}$. After heat treatment, those characteristic peaks of ZDMA can be still observed (Figure 1 curve b), illustrating that ZDMA is stable at $160^{\circ} \mathrm{C}$. For ZDMA/DBPMH blend (Figure 1 curve $\mathrm{c}$ and curve d), however, the band at $1651 \mathrm{~cm}^{-1}$ has disappeared after the heat

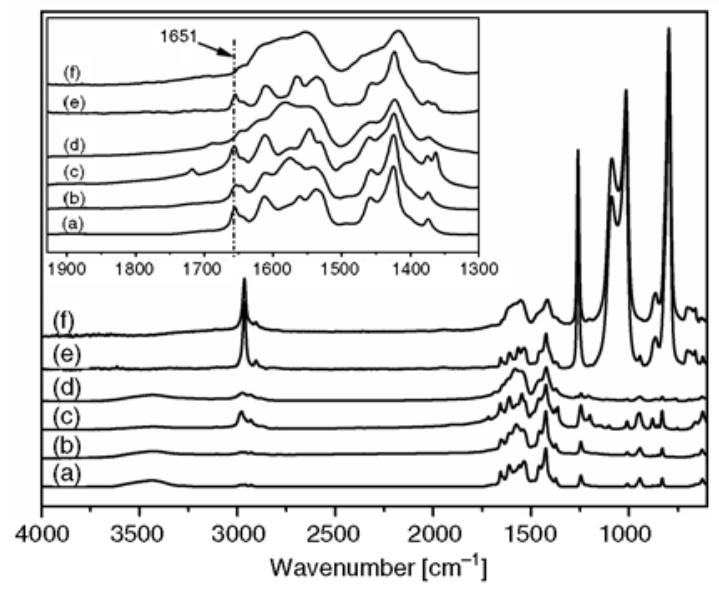

Figure 1. FTIR spectra of ZDMA (a) before and (b) after heat treatment, ZDMA/DBPMH blend (c) before and (d) after heat treatment and VMQ/ZDMA (100/40) composites containing 5 phr DBPMH (e) before and (f) after cured treatment. This result confirms that ZDMA has a high reactivity and most of ZDMA particles have reacted with the peroxide. In the spectrum of VMQ/ZDMA blend (Figure 1 curve e), the two sharp bands at $1015 \mathrm{~cm}^{-1}$ and $1087 \mathrm{~cm}^{-1}$ are attributed to the stretching vibration of $\mathrm{Si}-\mathrm{O}-\mathrm{Si}$, and the sharp band at $796 \mathrm{~cm}^{-1}$ is attributed to the stretching vibration of $\mathrm{Si}-\mathrm{C}$. The $\mathrm{C}=\mathrm{C}$ characteristics of $\mathrm{ZDMA}$ can be still observed in the blends, although the intensity of the peaks decreases as a result of the concentration effect. In the spectrum of VMQ/ZDMA composite (Figure 1 curve $\mathrm{f}$ ), the band at $1651 \mathrm{~cm}^{-1}$ has disappeared, indicating that most of the ZDMA participated in the in situ reaction in the VMQ matrix during the peroxide curing.

$\mathrm{X}$-ray diffraction (XRD) analysis was carried out to further verify the in situ reaction of ZDMA during the peroxide curing. Figure 2 shows the XRD patterns of ZDMA, ZDMA after heat treatment at $160^{\circ} \mathrm{C}$ for $15 \mathrm{~min}, \mathrm{ZDMA} / \mathrm{DBPMH}$ blend, ZDMA/ $\mathrm{DBPMH}$ blend after heat treatment at $160^{\circ} \mathrm{C}$ for 15 min, VMQ/ZDMA blend, and VMQ/ZDMA composite. ZDMA is highly crystalline and shows strong peaks at $2 \theta$ of $9.8,11.0,11.9,16.7$ and $22.1^{\circ}$, as shown in Figure 2 curve a. From the XRD patterns of ZDMA before and after heat treatment, it can be seen that there is almost no difference, meaning that the crystal structure of ZDMA was not destroyed by the heat treatment. The main characteristic peaks of ZDMA can be still observed in the ZDMA/DBPMH blend before heat treatment, as shown in Figure 2 curve c; after heat treatment, however, none of

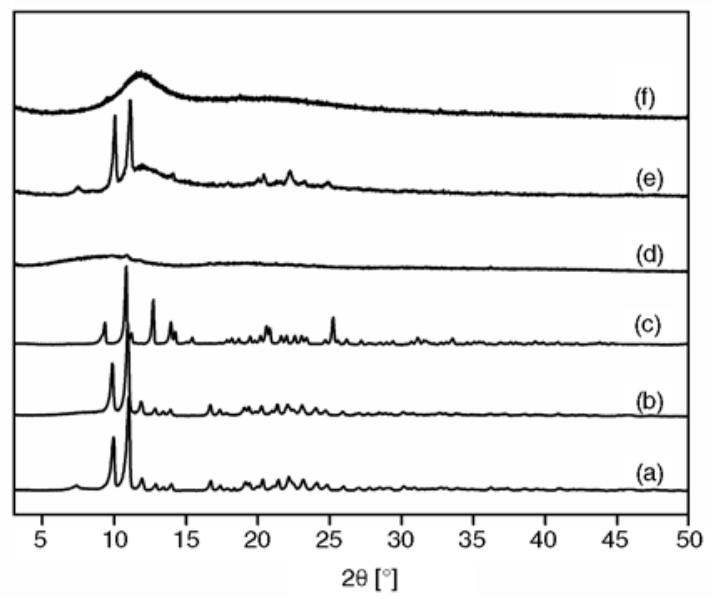

Figure 2. XRD patterns of ZDMA (a) before and (b) after heat treatment, ZDMA/DBPMH blend (c) before and (d) after heat treatment and VMQ/ZDMA (100/40) composites containing 5 phr DBPMH (e) before and (f) after cured 
those peaks can be detected (Figure 2 curve d). The result reveals that almost all the ZDMA crystals have transformed to amorphous state, which further confirms the reaction of ZDMA. In the pattern for the $\mathrm{VMQ} / \mathrm{ZDMA}$ blend (Figure 2 curve e), the strong characteristic peaks of ZDMA at $2 \theta=9.8$ and $11.0^{\circ}$ can be observed clearly. However, only a very broad diffraction peak of the VMQ matrix at $2 \theta=11.8^{\circ}$ can be detected in the VMQ/ZDMA composite, as shown in Figure 2 curve $f$. The result suggests that most of the ZDMA particles have participated in the in situ reaction during the peroxide curing and formed amorphous phases, consisting with the conclusion from the FTIR analysis.

On the basis of the above results and the results of previous studies on the in situ reactions of ZDMA $[22,27,28]$, the possible chemical reactions in the $\mathrm{VMQ} / \mathrm{ZDMA}$ blend during the peroxide curing are represented in Figure 3. During the peroxide curing, the peroxide is first decomposed to form free radi-

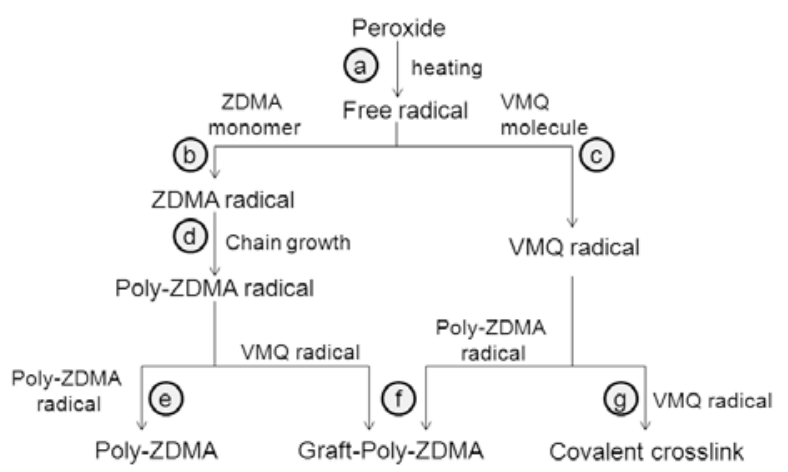

Figure 3. In-situ reaction in VMQ/ZDMA blend during peroxide curing: (a) decomposition of peroxide by heating, (b) ZDMA is initiated to form ZDMA radical, (c) VMQ is initiated to form VMQ radical, (d) chain growth of poly-ZDMA, (e) termination of poly-ZDMA chain, (f) graft reaction between VMQ and poly-ZDMA, and (g) generation of covalent crosslinks

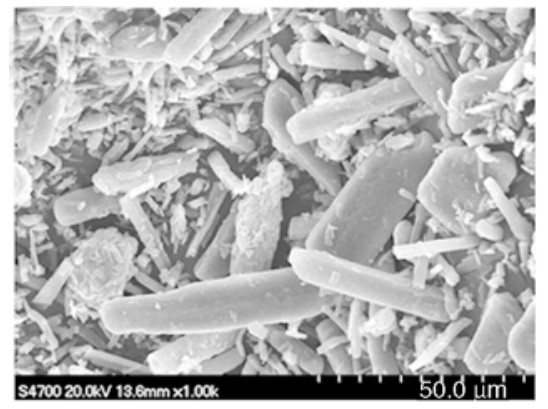

a)

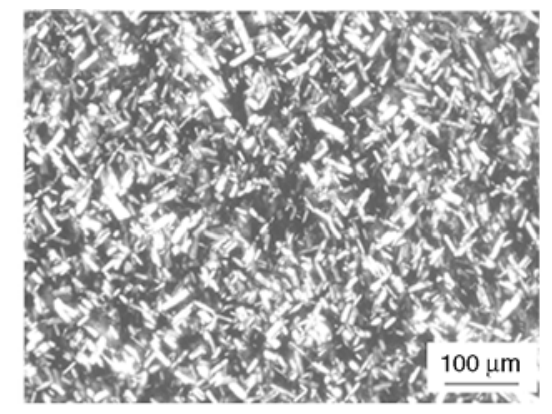

b) cals, which will react with the ZDMA monomers and silicone rubber chains to form ZDMA radicals and VMQ radicals, respectively. A ZDMA radical initiates its monomer to form a poly-ZDMA radical, which will be terminated with another poly-ZDMA radical to form poly-ZDMA or terminated with a VMQ radical to form grafted poly-ZDMA. Simultaneously, the covalent bonds between the rubber chains are formed by the reaction of VMQ radicals.

\subsection{Morphology analysis}

The SEM image in Figure 4a shows the morphology of the original ZDMA particles. These particles are in the shape of rod (ratio of length to diameter, $L / D-5$ and length $5-50 \mu \mathrm{m})$. The polarizing optical microscopy (POM) image of the VMQ/ZDMA blend is shown in Figure 4b. The dark phase is the silicone rubber matrix (silicone rubber is amorphous at room temperature), and the bright phase represents the ZDMA crystals. The size and shape of the ZDMA particles in the VMQ matrix don't change much over those of the original ZDMA particles shown in the SEM image (Figure 4a) because the shear stress generated by the silicone rubber is too low to grind the ZDMA particles. It implies that it is difficult to get a good dispersion of ZDMA in VMQ matrix via simple mechanical blending. After curing, however, the bright phases have darkened or disappeared, as shown in Figure 4c, implying that the crystalline structure of ZDMA was destroyed in the peroxide curing, possibly because of the in situ reaction of ZDMA. In the cured VMQ/ZDMA composites, some amorphous particles at the micro-level can be observed. These particles are probably composed of unreacted ZDMA and poly-ZDMA particles generated by the polymerization of ZDMA.

Some previous studies focused on the transformation of metal salts of unsaturated carboxylic acids

Figure 4. (a) SEM micrograph of ZDMA, and POM images of (b) uncured and (c) cured VMQ/ZDMA (100/40) composites containing 5 phr DBPMH 


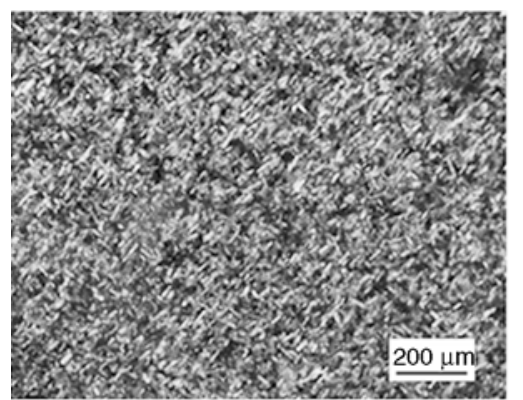

a)

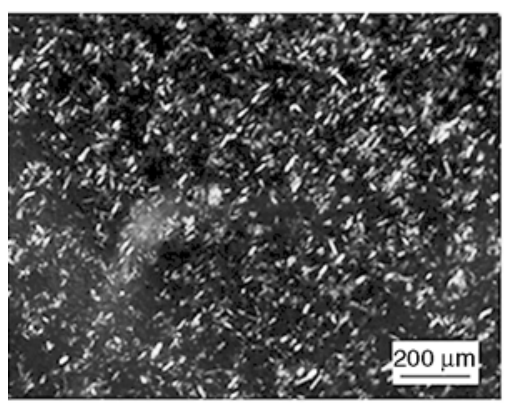

d)

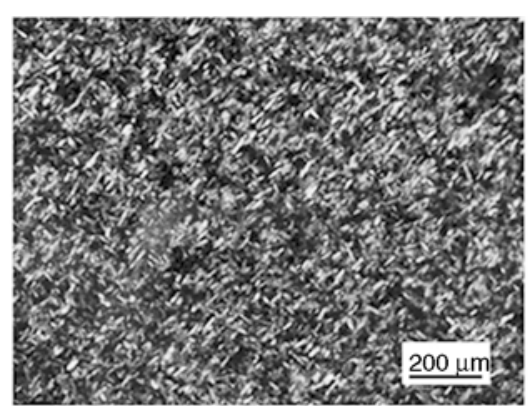

b)

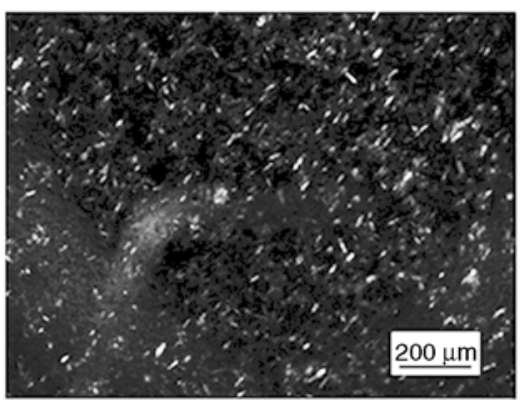

e)

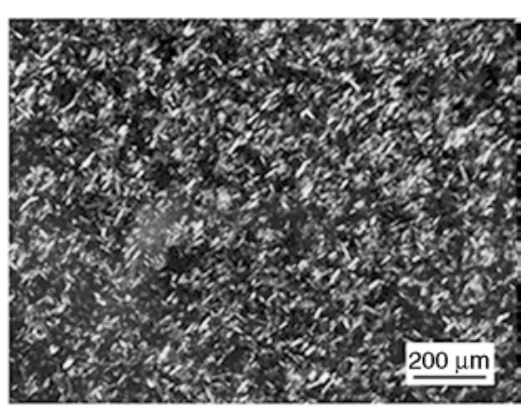

c)

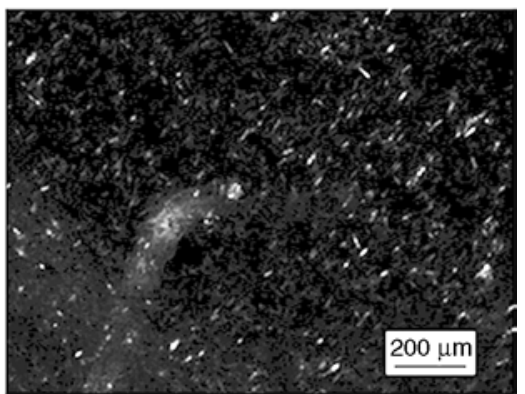

f) $160^{\circ} \mathrm{C}(15 \mathrm{~min})$

Figure 5. POM images of VMQ/ZDMA blends (100/40) containing 5 phr DBPMH during the heat treatment

by contrasting the morphology of the vulcanizates to that of the blends $[23,27]$. In the present study, we used POM to observe the transformation of ZDMA crystals in situ during the peroxide curing. The change of the ZDMA crystals, as shown in Figure 5, was recorded by the polarizing optical microscope for 15 minutes. During the peroxide curing, the size of ZDMA crystals decreases gradually, and almost all the crystals disappear at the end. As illustrated in the XRD analysis, the reaction of ZDMA induced by peroxide radicals can destroy the crystalline structure. Therefore, the disappearance of ZDMA crystals in the VMQ/ZDMA blend during the peroxide curing is probably attributed to the in situ reaction of ZDMA. Besides, the melting of ZDMA crystals and the dissolving of ZDMA into silicone rubber are also possible reasons for the disappearance of ZDMA crystals. To further study the transformation of ZDMA crystals in silicone rubber at high temperature, the thermal behavior of ZDMA was investigated by DSC, as shown in Figure 6. The DSC heating curve (Figure 6a) shows two endothermic peaks at 186 and $218^{\circ} \mathrm{C}$, corresponding to two different ZDMA crystalline structure. At high temperature (about $300^{\circ} \mathrm{C}$ ), a strong exothermic peak can be observed, indicating that some reaction of ZDMA occurs. In the isothermal DSC curve of ZDMA at $160^{\circ} \mathrm{C}$ (Figure 6b), neither endothermic nor exothermic peak can be observed, implying that
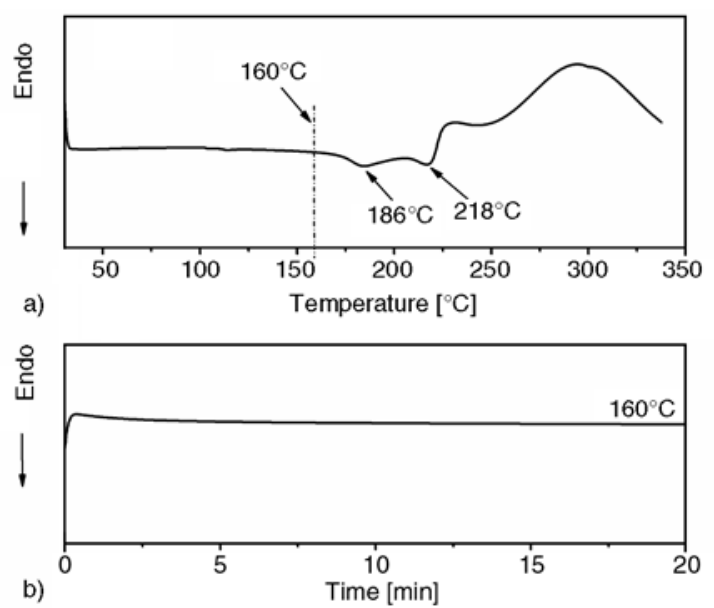

Figure 6. DSC curves of ZDMA under nitrogen atmosphere (a) DSC heating curve, (b) isothermal DSC curve

ZDMA is quite stable at $160^{\circ} \mathrm{C}$ and the disappearance of ZDMA crystals during the peroxide curing should not be attributed to the crystal melting. Figure 7 shows the transformation of ZDMA in the VMQ/ZDMA blend without peroxide when the blend was kept at $160^{\circ} \mathrm{C}$ for $15 \mathrm{~min}$. At the beginning of heating process, the size of ZDMA decreases gradually, probably due to the dissolving of ZDMA into silicone rubber since the melting of crystals does not occur according to the DSC analysis. However, great quantities of ZDMA crystals can be still observed at the end of heating process. Comparing the POM images of VMQ/ZDMA blend containing peroxide with those of VMQ/ZDMA blend 


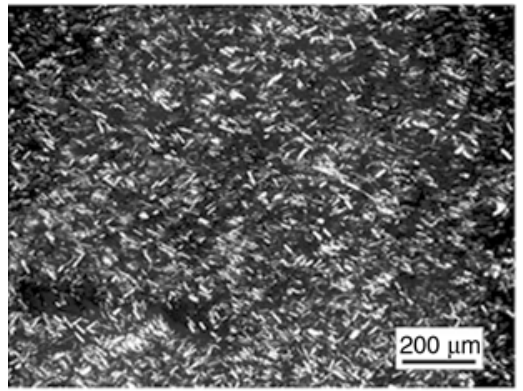

a)

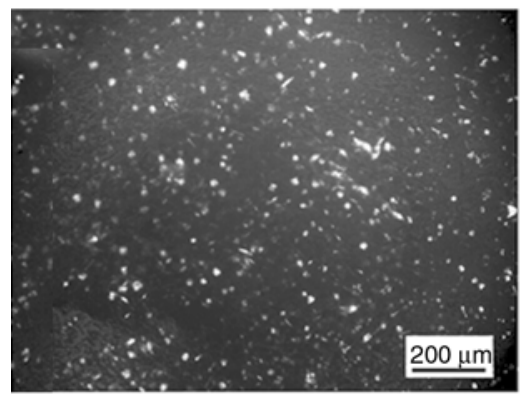

d)

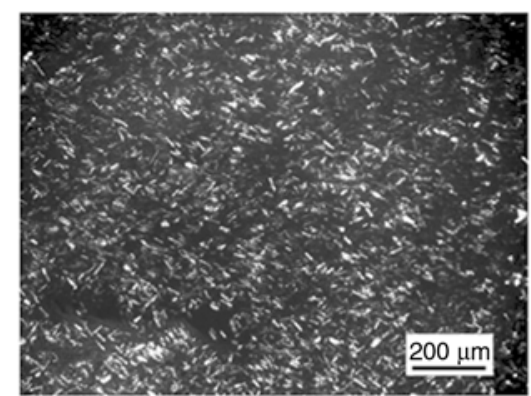

b)

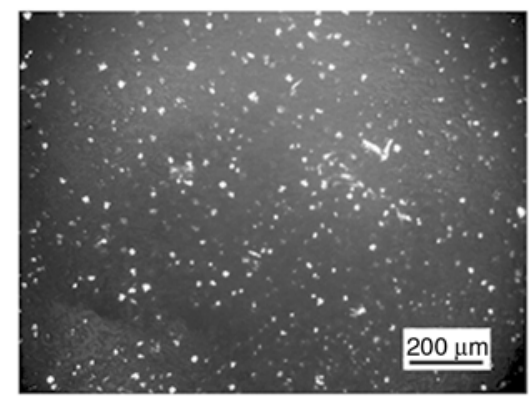

e)

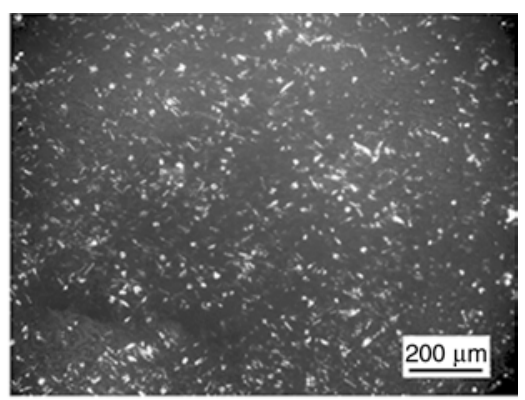

c)

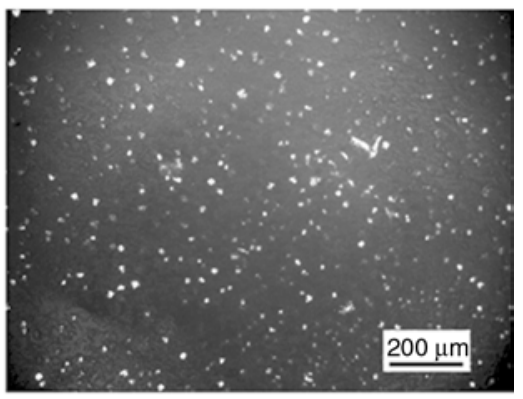

f)

$160^{\circ} \mathrm{C}(15 \mathrm{~min})$

Figure 7. POM images of VMQ/ZDMA blends (100/40) without peroxide during the heat treatment

without peroxide, we can conclude that the in situ reaction of ZDMA during the peroxide curing plays an important role on the transformation of ZDMA from crystalline state to amorphous state.

Transmission electron microscopy (TEM) and high resolution transmission electron microscopy (HRTEM) were performed to observe the morphology of VMQ/ZDMA composites at the nano-level. Figure 8a shows the TEM morphology of VMQ/ ZDMA composites. In the VMQ/ZDMA composites, micro-level particles can still be observed. However, the crystalline structure of these particles was likely destroyed because the crystals would split from the VMQ matrix to form cavities during the preparation of the samples. In the TEM photograph at high magnification, uniform dark phases at the nano-level can be observed, as shown in Figure $8 a_{1}$. The HRTEM images given in Figure $8 b-d$ clearly show that there are significant amounts of nano-dispersed structures (the darker phase) forming in the composites. These nano-dispersed structures, which are about $5-10 \mathrm{~nm}$ in diameter, represent poly-ZDMA aggregates or poly-ZDMA ionic clusters [23, 28-32] produced by the in situ polymerization of ZDMA during the peroxide curing.

The TEM observations indicate that uniform nanolevel dispersion can be obtained via the in situ reaction method even though the original dispersion of ZDMA is poor. The 'dissolving-diffusion' mecha- nism of nanodispersion generation, which has been accepted by some researchers [28, 31, 32], was used to illustrate the transformation of ZDMA in VMQ matrix, as shown in Figure 9. During the peroxide curing, the ZDMA monomers dissolved in the VMQ matrix and on the surface of the micro-level ZDMA crystals homo-polymerize or graft onto the silicone rubber chains with peroxide. The generated polyZDMA particles separate from the ZDMA crystals and disperse in the VMQ matrix. As a result, the inner monomers of the ZDMA crystals are exposed for further reaction, and the size of ZDMA particles decreased gradually. On the other hand, because of the formation of grafted poly-ZDMA, the compatibility between the silicone rubber and ZDMA is probably improved to some extent. The improved compatibility is beneficial to further diffusion of ZDMA monomers. With the in situ polymerization, the dissolving-diffusion balance of the ZDMA monomers in the VMQ matrix is broken, leading to a continual diffusion of these monomers from the particles into the matrix to participate in the in situ polymerization. Ultimately, a nano-dispersion is obtained.

\subsection{Mechanical properties}

We studied the effect of ZDMA on the mechanical properties of VMQ because ZDMA has been shown to be an effective reinforcing agent for elastomers 


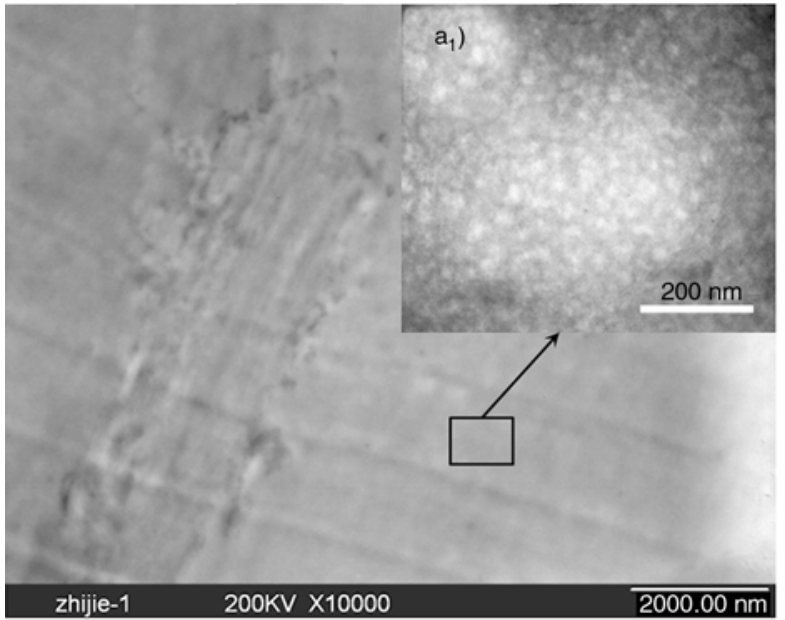

a)

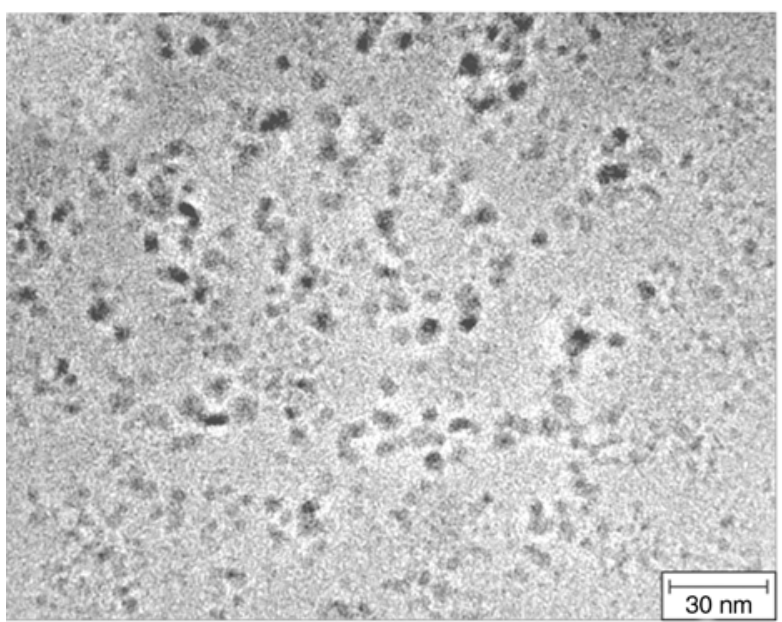

c)

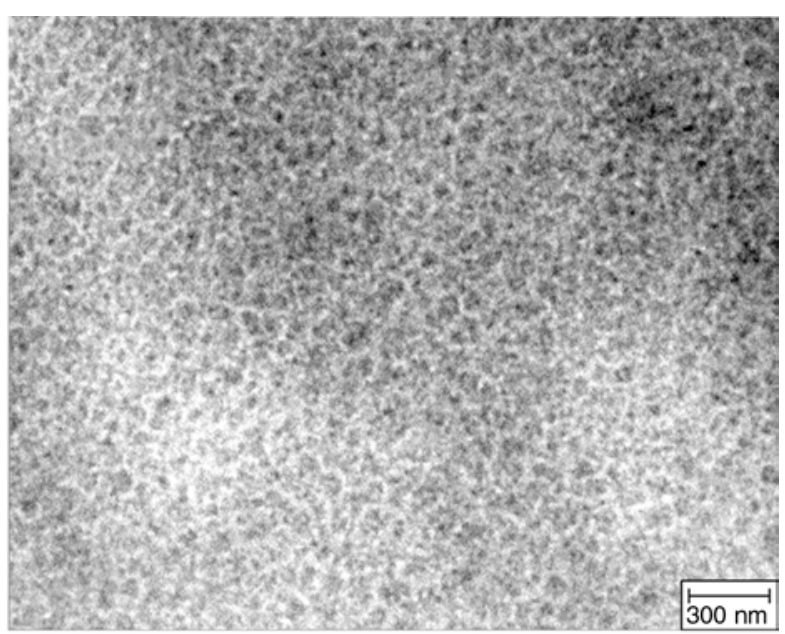

b)

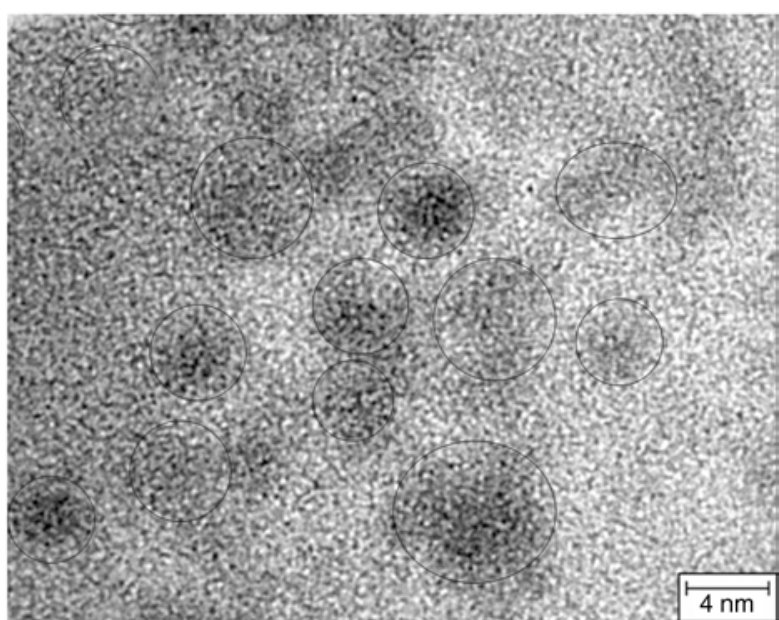

d)

Figure 8. (a) TEM morphology and (c-d) HRTEM morphology of the cured VMQ/ZDMA composite containing 40 phr ZDMA and 5 phr DBPMH

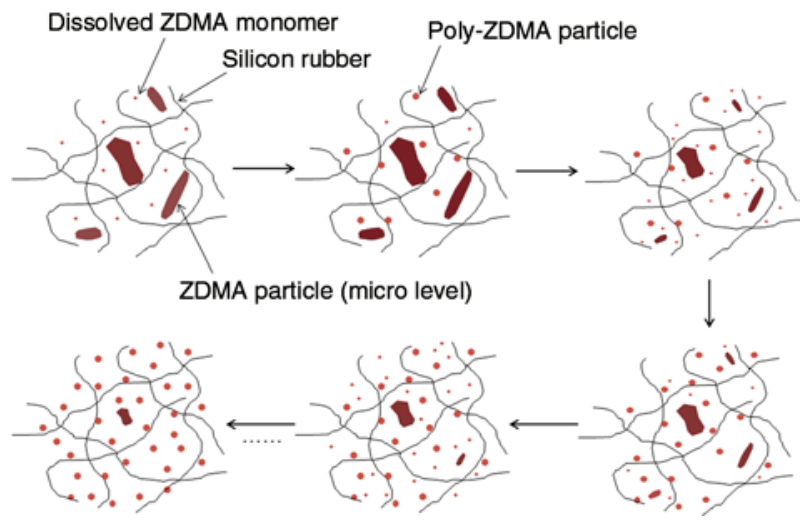

Figure 9. Schematic representation for the formation of nanophases in silicone rubber matrix during the peroxide curing

[22]. Since a considerable amount of radicals generated by peroxide was consumed by ZDMA, the amount of peroxide should be an important factor for the mechanical properties of VMQ/ZDMA composites. In this work, the effect of the amount of peroxide on the mechanical properties of VMQ/ ZDMA was investigated first. Table 1 show the mechanical properties of VMQ/ZDMA (100/30) composites. With increasing the amount of DBPMH, the modulus at $100 \%$ strain and Shore A hardness increase, but the elongation at break decreases gradually. The tensile strength shows a maximum value of $4.08 \mathrm{MPa}$ when the amount of DBPMH is $5 \mathrm{phr}$. The amount of ZDMA also affects the tear strength of VMQ/ZDMA composites. With increasing the amount of DBPMH, the tear strength increase at first and then tends to stable when the amount of ZDMA is higher than $3 \mathrm{phr}$. The content of DBPMH has little influence on the permanent set of VMQ/ ZDMA composites, and the value keeps at a low level for all the samples (below 5\%). Additionally, it can be seen that the elongation at break (over $350 \%)$ is still high even when the amount of DBPMH is as high as $6 \mathrm{phr}$. It is a characteristic 
Table 1. Mechanical properties of VMQ/ZDMA (100/30) composites with different amount of DBPMH

\begin{tabular}{|l|c|c|c|c|c|c|}
\hline \multicolumn{1}{|c|}{ Samples } & $\begin{array}{c}\mathbf{1 0 0 \%} \text { modulus } \\
{[\mathbf{M P a}]}\end{array}$ & $\begin{array}{c}\text { Tensile strength } \\
{[\mathbf{M P a}]}\end{array}$ & $\begin{array}{c}\text { Shore A } \\
\text { hardness } \\
{\left[{ }^{\circ}\right]}\end{array}$ & $\begin{array}{c}\text { Tear strength } \\
{[\mathbf{k N} / \mathbf{m}]}\end{array}$ & $\begin{array}{c}\text { Elongation at } \\
\text { break } \\
{[\mathbf{1 0 0} \%]}\end{array}$ & $\begin{array}{c}\text { Permanent set } \\
{[\mathbf{1 0 0 \%}]}\end{array}$ \\
\hline DBPMH 1 phr & $0.30( \pm 0.01)$ & $1.16( \pm 0.02)$ & 21 & $4.20( \pm 0.05)$ & $529( \pm 28)$ & 4 \\
\hline DBPMH 2 phr & $0.51( \pm 0.03)$ & $2.24( \pm 0.06)$ & 30 & $7.31( \pm 0.25)$ & $483( \pm 20)$ & 4 \\
\hline DBPMH 3 phr & $0.67( \pm 0.03)$ & $2.75( \pm 0.08)$ & 35 & $8.22( \pm 0.10)$ & $423( \pm 20)$ & 3 \\
\hline DBPMH 4 phr & $0.83( \pm 0.04)$ & $3.64( \pm 0.21)$ & 39 & $8.42( \pm 0.34)$ & $409( \pm 18)$ & 2 \\
\hline DBPMH 5 phr & $0.95( \pm 0.03)$ & $4.08( \pm 0.21)$ & 40 & $8.08( \pm 0.41)$ & $380( \pm 17)$ & 2 \\
\hline DBPMH 6 phr & $0.97( \pm 0.04)$ & $3.70( \pm 0.07)$ & 40 & $8.18( \pm 0.52)$ & $363( \pm 17)$ & 2 \\
\hline
\end{tabular}

property of metal salts of unsaturated carboxylic acids that they impart high strength and hardness, while allowing the rubber to retain a high elongation at break [29].

The effect of amount of ZDMA on the mechanical properties of VMQ/ZDMA composites was investigated next. Figure 10 shows the curing characteristics of VMQ/ZDMA blends containing $5 \mathrm{phr}$ DBPMH. The maximum torque (MH) decreases with increasing the amount of ZDMA, but the minimum torque (ML) doesn't change much. Generally, the difference between maximum torque and minimum torque (MH-ML) is related to the crosslink density of the composites; for a given formula, high value corresponds to high crosslink density. The result implies that the incorporation of ZDMA will affect the crosslink structure of silicone rubber. Additionally, the optimum curing time $\left(t_{90}\right)$ increases greatly when ZDMA is incorporated into VMQ matrix, probably ascribed to the consumption of peroxide radicals by ZDMA.

The mechanical properties of VMQ/ZDMA composites containing $5 \mathrm{phr}$ DBPMH are shown in Table 2. The tensile strength and elongation at break exhibit maximums when the amount of ZDMA is 40 and $30 \mathrm{phr}$, respectively. The maximum tensile

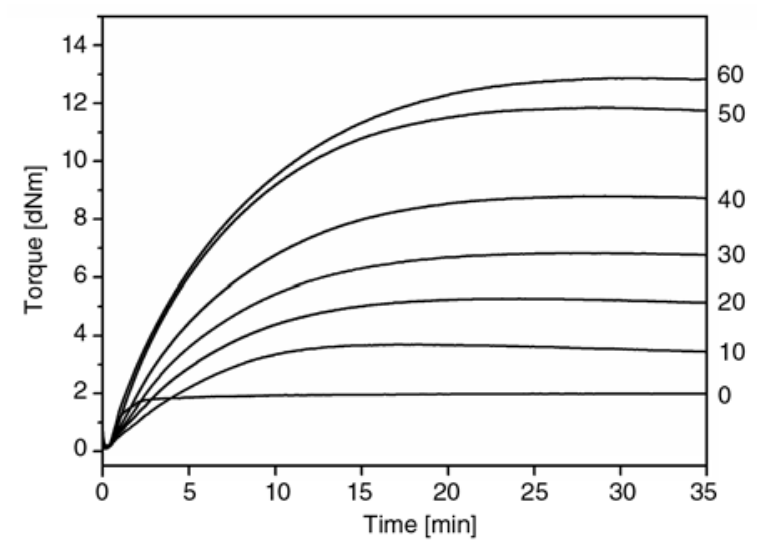

Figure 10. The curing curves of VMQ/ZDMA blends with different amount of ZDMA strength is $4.50 \mathrm{MPa}$ and the maximum elongation at break is $380 \%$. The tear strength also shows a maximum $(9.05 \mathrm{kN} / \mathrm{m})$ when the amount of ZDMA is $50 \mathrm{phr}$. Both the modulus at $100 \%$ strain and Shore A hardness increase significantly with increasing the amount of ZDMA. The permanent set of VMQ/ZDMA composites also increases with increasing the amount of ZDMA, but the value keeps at a low level for all the samples (below 5\%). Considering the mechanical properties of gum VMQ vulcanizate shown in Table 2 (ZDMA 0 phr), we can conclude that ZDMA has a significant reinforcing effect on VMQ. For example, when $40 \mathrm{phr}$ ZDMA is incorporated into VMQ matrix, both the tensile strength and tear strength increase by more than 10 times. The typical stress-strain curves of VMQ/ ZDMA composites with different amount of ZDMA are presented in Figure 11. It can be seen that the incorporation of ZDMA can greatly increase the modulus of VMQ vulcanizates, especially at the low elongation.

In summary, both the amount of peroxide and the amount of ZDMA play important roles on the mechanical properties of $\mathrm{VMQ} / \mathrm{ZDMA}$ composites. The best mechanical properties of VMQ/ZDMA composites are obtained when the DBPMH amount

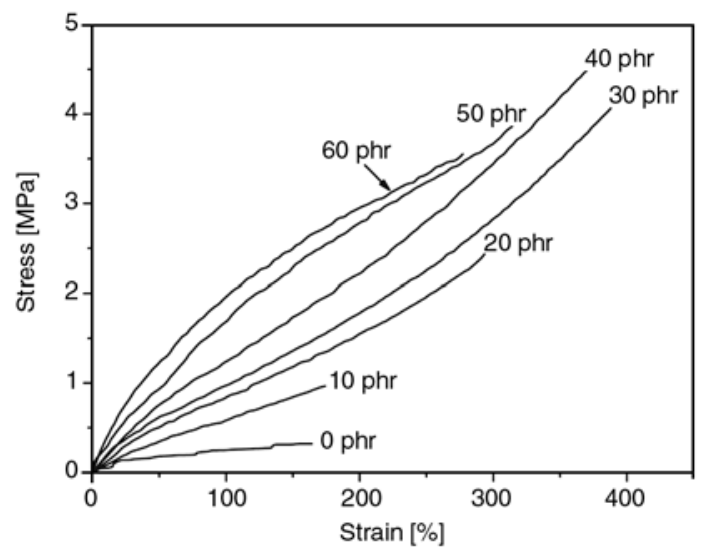

Figure 11. Stress-strain curves of VMQ/ZDMA blends with different amount of ZDMA 
Table 2. Mechanical properties of VMQ/ZDMA composites with different amount of ZDMA

\begin{tabular}{|l|c|c|c|c|c|c|}
\hline \multicolumn{1}{|c|}{ Samples } & $\begin{array}{c}\mathbf{1 0 0 \%} \\
{[\mathbf{M P a}]}\end{array}$ & $\begin{array}{c}\text { Tensile strength } \\
{[\mathbf{M P a}]}\end{array}$ & $\begin{array}{c}\text { Shore A } \\
\text { hardness } \\
{\left[{ }^{\circ}\right]}\end{array}$ & $\begin{array}{c}\text { Tear strength } \\
{[\mathbf{k N} / \mathbf{m}]}\end{array}$ & $\begin{array}{c}\text { Elongation at } \\
\text { break } \\
{[\mathbf{1 0 0 \%}]}\end{array}$ & $\begin{array}{c}\text { Permanent set } \\
{[\mathbf{1 0 0 \%}]}\end{array}$ \\
\hline ZDMA 0 phr & $0.25( \pm 0.06)$ & $0.35( \pm 0.13)$ & 19 & $0.67( \pm 0.04)$ & $160( \pm 22)$ & 0 \\
\hline ZDMA 10 phr & $0.54( \pm 0.05)$ & $0.97( \pm 0.13)$ & 32 & $3.04( \pm 0.22)$ & $163( \pm 28)$ & 0 \\
\hline ZDMA 20 phr & $0.78( \pm 0.03)$ & $2.48( \pm 0.07)$ & 35 & $4.73( \pm 0.28)$ & $292( \pm 19)$ & 2 \\
\hline ZDMA 30 phr & $0.95( \pm 0.03)$ & $4.08( \pm 0.21)$ & 40 & $8.08( \pm 0.41)$ & $380( \pm 17)$ & 2 \\
\hline ZDMA 40 phr & $1.37( \pm 0.04)$ & $4.50( \pm 0.15)$ & 45 & $8.71( \pm 0.14)$ & $373( \pm 11)$ & 4 \\
\hline ZDMA 50 phr & $1.75( \pm 0.03)$ & $3.93( \pm 0.10)$ & 53 & $9.05( \pm 0.33)$ & $313( \pm 13)$ & 4 \\
\hline ZDMA 60 phr & $1.96( \pm 0.06)$ & $3.64( \pm 0.09)$ & 57 & $8.95( \pm 0.42)$ & $276( \pm 24)$ & 4 \\
\hline
\end{tabular}

and VMQ amount are 5 and $40 \mathrm{phr}$, respectively. However, the reinforcing effect of ZDMA is lower on silicone rubber than on other elastomers such as HNBR, EPDM, and NBR, possibly because of the poor dispersion of ZDMA in the VMQ blend. The TEM and POM images showed that large ZDMA particles cannot diffuse completely into the VMQ matrix to form a uniform nanodispersion, but become amorphous particles at the micro-level instead. These micro-level particles have a negative effect on the mechanical properties.

\subsection{Crosslink structure of VMQ/ZDMA composites}

The competitive reactions of peroxide-initiated polymerization of ZDMA and cross linking of polymer occur simultaneously during the peroxide curing of the blend. In rubber/ZDMA composites, there are not only covalent crosslinks between the rubber chains but also ionic crosslinks mainly formed by the grafted poly-ZDMA, as shown in Figure 12. Because the ionic crosslinks have been known [22, $29,30]$ to play an important role on the mechanical properties of rubber/ZDMA composites, it is significant and necessary to investigate the crosslink structure of the VMQ/ZDMA composites.

Figure 13 shows the FTIR spectra of VMQ/ZDMA composites before and after acidolysis. After aci-

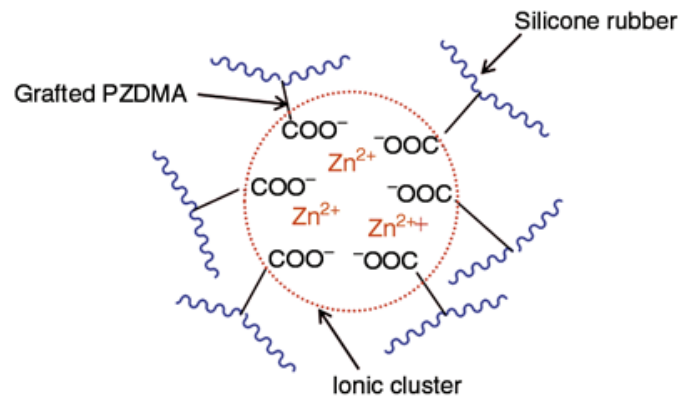

Figure 12. Schematic representation of ionic crosslink

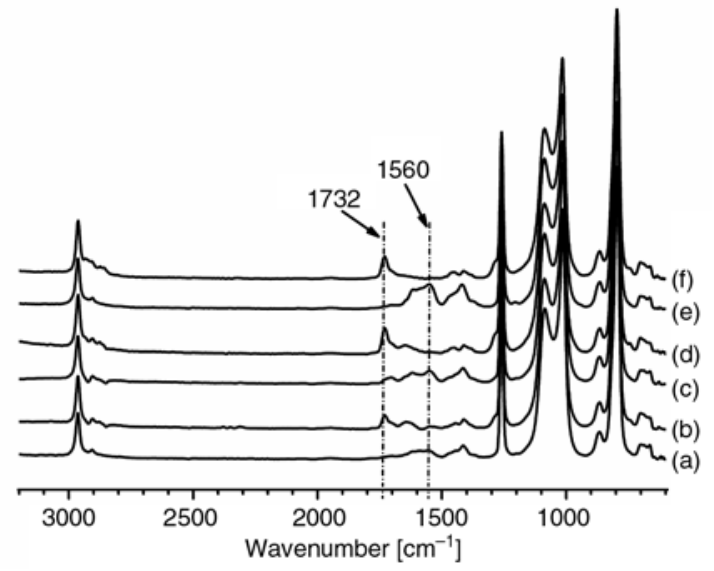

Figure 13. FTIR spectra of samples: (a) VMQ/ZDMA (100/20) vulcanizate before acidolysis, (b) VMQ/ ZDMA (100/20) vulcanizate after acidolysis, (c) VMQ/ZDMA (100/40) vulcanizate before acidolysis, (d) VMQ/ZDMA (100/40) vulcanizate after acidolysis, (e) VMQ/ZDMA (100/60) vulcanizate before and (f) VMQ/ZDMA (100/60) vulcanizate after acidolysis

dolysis, the band corresponding to $-\mathrm{COO}-$ at $1560 \mathrm{~cm}^{-1}$ has disappeared, and a new stretching vibration band corresponding to $-\mathrm{COOH}$ was observed at $1732 \mathrm{~cm}^{-1}$. These results confirmed that the hydrolysis of poly-ZDMA was quite thorough, and almost all the $\mathrm{Zn}^{2+}$ had been replaced by $\mathrm{H}^{+}$during hydrolysis. The FTIR spectra also confirmed that parts of the poly-ZDMA were grafted onto silicone rubber chains during the peroxide curing because both the ungrafted poly-ZDMA and residual unreacted ZDMA could be extracted from the samples during the Soxhlet extraction treatment.

Figure 14 shows that with increasing the amount of ZDMA, the gross crosslink density and ionic crosslink density of VMQ/ZDMA composites increase gradually, but the covalent crosslink density decreases slightly. Looking at the results of the 


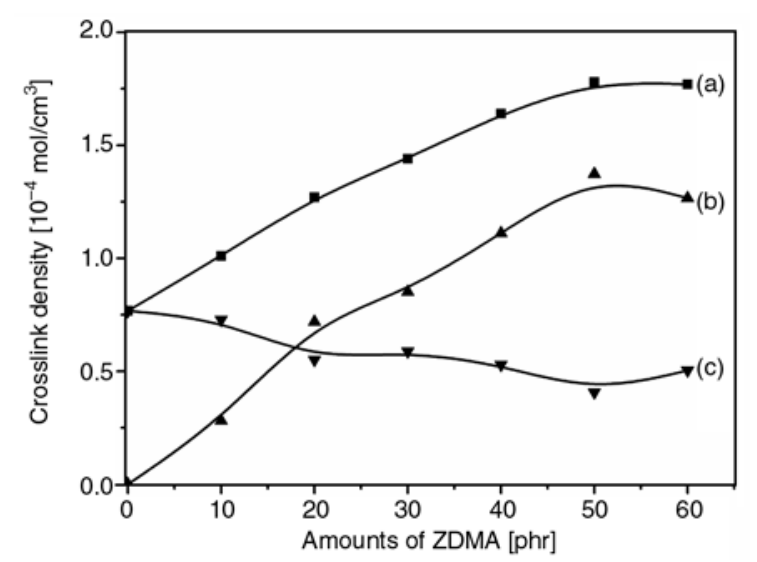

Figure 14. Effect of ZDMA loading on the crosslink density of VMQ/ZDMA composites containing 5 phr DBPMH: (a) gross crosslink density, (b) ionic crosslink density and (c) covalent crosslink density

crosslink density and the mechanical properties of $\mathrm{VMQ} / Z D M A$ composites, we can conclude that the ionic crosslink structure has a close relationship with the mechanical properties. The composite with high ionic crosslink density exhibits high hardness and modulus at $100 \%$ strain; high ionic crosslink density is also favorable to high tensile strength and elongation at break at the low ZDMA contents. However, the ionic crosslink content is lower in VMQ/ZDMA composites than in other rubber/ ZDMA composites such as HNBR/ZDMA composites and NBR/ZDMA composites. For example, in the VMQ/ZDMA composite containing $40 \mathrm{phr}$ ZDMA, ionic crosslinks account for only $67 \%$ of gross crosslinks, but the content of ionic crosslinks is higher than $85 \%$ in HNBR/ZDMA composites [31]. The low content of vinyl substituent $(0.15 \%)$ in silicone rubber is possibly one reason for the low content of ionic crosslinks. As illustrated in Figure 3, grafted poly-ZDMA is formed by the reaction between poly-ZDMA radicals and VMQ radicals. Because of the low content of VMQ radicals, which are mainly generated from the vinyl substituent, the content of grafted poly-ZDMA is low. As a result, the $\mathrm{VMQ} / \mathrm{ZDMA}$ composites have relatively low contents of ionic crosslinks. Additionally, the poor dispersion of ZDMA in VMQ blends decreases the contact area of the ZDMA particles and VMQ matrix and would do harm to the grafting reaction, leading to a low content of ionic crosslinks.

\section{Conclusions}

During the peroxide curing, ZDMA homo-polymerized to form poly-ZDMA or grafted onto silicone rubber chains to form grafted poly-ZDMA, and the conversion of ZDMA was almost complete as shown by the FTIR and XRD analyses. Because of the in situ reaction of ZDMA, the micro-level ZDMA particles gradually got smaller. In the composites, a uniform nano-dispersed structure (the aggregation of poly-ZDMA and grafted polyZDMA) was formed. A 'dissolving-diffusion' model was used in previous studies to illustrate the transformation of ZDMA in the VMQ matrix. This model suggests that a uniform nano-dispersed structure can be obtained via the in situ reaction even though the initial dispersion of ZDMA in the blend is poor. ZDMA has a significant reinforcement for silicone rubber. Both the amount of peroxide and the amount of ZDMA affect the mechanical properties of VMQ/ZDMA composites significantly, and the best mechanical properties of VMQ/ZDMA composites are obtained when the amount of DBPMH and the amount of ZDMA are 5 and $40 \mathrm{phr}$, respectively. The addition of ZDMA into VMQ introduced a large amount of ionic crosslinks, which plays an important role on the mechanical properties. As the amount of ZDMA increases, the gross crosslink density and ionic crosslink density increase, but the covalent crosslink density decreases slightly.

\section{Acknowledgements}

This research was financially supported by the National Science Fund for Distinguished Young Scholars (50725310) and the Program for Changjiang Scholars and Innovative Research Team in University (PCSIRT, IRT0807).

\section{References}

[1] Clarson S. J.: Silicones and silicone-modified materials: A concise overview. in 'Synthesis and properties of silicones and silicone-modified materials' (eds.: Clarson S. J., Fitzgerald J. J., Owen M. J., Smith S. D., Van Dyke M. E.) American Chemical Society, Washington, Vol 838, 1-10 (2003).

DOI: $10.1021 / \mathrm{bk}-2003-0838 . c h 001$

[2] Mark J. E.: Overview of siloxane polymers. in 'Silicones and silicone-modified materials' (eds.: Clarson S. J., Fitzgerald J. J., Owen M. J., Smith S. D.) American Chemical Society, Washington, Vol 729, 1-10 (2000).

DOI: $10.1021 / \mathrm{bk}-2000-0729 . \mathrm{ch} 001$ 
[3] McMillin C. R.: Biomedical applications of rubbers and elastomers. Rubber Chemistry and Technology, 79, 500-519 (2006).

DOI: $10.5254 / 1.3547948$

[4] Sandén R.: Castable silicone based heat insulations for jet engines. Polymer Testing, 21, 61-64 (2002). DOI: $10.1016 / \mathrm{S} 0142-9418(01) 00048-4$

[5] Saleem A., Frormann L., Soever A.: Fabrication of extrinsically conductive silicone rubbers with high elasticity and analysis of their mechanical and electrical characteristics. Polymers, 2, 200-210 (2010). DOI: $10.3390 /$ polym2030200

[6] Xu Q., Pang M., Zhu L., Zhang Y., Feng S.: Mechanical properties of silicone rubber composed of diverse vinyl content silicone gums blending. Materials and Design, 31, 4083-4087 (2010).

DOI: $10.1016 /$ j.matdes.2010.04.052

[7] Ahmad Z., Mark J. E.: Biomimetic materials: Recent developments in organic-inorganic hybrids. Materials Science and Engineering: C, 6, 183-196 (1998). DOI: 10.1016/S0928-4931(98)00044-7

[8] Paul D. R., Mark J. E.: Fillers for polysiloxane ('silicone') elastomers. Progress in Polymer Science, 35, 893-901 (2010). DOI: 10.1016/j.progpolymsci.2010.03.004

[9] LeBaron P. C., Pinnavaia T. J.: Clay nanolayer reinforcement of a silicone elastomer. Chemistry of Materials, 13, 3760-3765 (2001).

DOI: $10.1021 / \mathrm{cm} 010982 \mathrm{~m}$

[10] Frogley M. D., Ravich D., Wagner H. D.: Mechanical properties of carbon nanoparticle-reinforced elastomers. Composites Science and Technology, 63, 16471654 (2003).

DOI: $10.1016 / \mathrm{S} 0266-3538(03) 00066-6$

[11] Liu L., Tian M., Zhang W., Zhang L., Mark J. E.: Crystallization and morphology study of polyhedral oligomeric silsesquioxane (POSS)/polysiloxane elastomer composites prepared by melt blending. Polymer, 48, 3201-3212 (2007).

DOI: $10.1016 /$ j.polymer.2007.03.067

[12] Pan G., Mark J. E., Schaefer D. W.: Synthesis and characterization of fillers of controlled structure based on polyhedral oligomeric silsesquioxane cages and their use in reinforcing siloxane elastomers. Journal of Polymer Science Part B: Polymer Physics, 41, 3314 3323 (2003).

DOI: $10.1002 /$ polb.10695

[13] Alexandru M., Cazacu M., Doroftei F., Ignat M., Timpu D., Grigoras C. V., Simionescu B. C.: On the morphology and potential application of polydimethylsiloxane-silica-titania composites. Express Polymer Letters, 5, 188-196 (2011). DOI: $10.3144 /$ expresspolymlett.2011.17

[14] Mark J. E., Pan S-J.: Reinforcement of polydimethylsiloxane networks by in-situ precipitation of silica: A new method for preparation of filled elastomers. Macromolecular Rapid Communications, 3, 681-685 (1982). DOI: $\underline{10.1002 / \text { marc. } 1982.030031006}$
[15] Ning Y-P., Tang M-Y., Jiang C-Y., Mark J. E., Roth W. C.: Particle sizes of reinforcing silica precipitated into elastomeric networks. Journal of Applied Polymer Science, 29, 3209-3212 (1984).

DOI: 10.1002/app.1984.070291022

[16] Bokobza L., Diop A. L.: Reinforcement of poly (dimethylsiloxane) by sol-gel in situ generated silica and titania particles. Express Polymer Letters, 4, 355363 (2010).

DOI: $10.3144 /$ expresspolymlett.2010.45

[17] Wen J., Mark J. E.: Synthesis, structure, and properties of poly(dimethylsiloxane) networks reinforced by in situ-precipitated silica-titania, silica-zirconia, and silica-alumina mixed oxides. Journal of Applied Polymer Science, 58, 1135-1145 (1995).

DOI: 10.1002/app.1995.070580707

[18] Song S-S., Qi H-B., Wu Y-P.: Preparation and properties of water-absorbent composites of chloroprene rubber, starch, and sodium acrylate. Polymers for Advanced Technologies, 22, 1778-1785 (2011).

DOI: $10.1002 /$ pat.1671

[19] Yin D. H., Zhang Y., Peng Z. L., Zhang Y. X.: A comparison between the SBR vulcanizates reinforced by magnesium methacrylate added directly or prepared in situ. European Polymer Journal, 39, 99-105 (2003). DOI: 10.1016/S0014-3057(02)00171-4

[20] Du A., Peng Z., Zhang Y., Zhang Y.: Effect of magnesium methacrylate on the mechanical properties of EVM vulcanizate. Polymer Testing, 21, 889-895 (2002).

DOI: 10.1016/S0142-9418(02)00025-9

[21] Wen S., Zhang X., Hu S., Zhang L., Liu L.: Influence of in-situ reaction on luminescent properties of samarium-complex/hydrogenated acrylonitrile-butadiene composites. Polymer, 50, 3269-3274 (2009). DOI: $10.1016 /$ j.polymer.2009.05.009

[22] Lu Y., Liu L., Tian M., Geng H., Zhang L.: Study on mechanical properties of elastomers reinforced by zinc dimethacrylate. European Polymer Journal, 41, 589598 (2005). DOI: 10.1016/j.eurpolymj.2004.10.012

[23] Lu Y., Liu L., Yang C., Tian M., Zhang L.: The morphology of zinc dimethacrylate reinforced elastomers investigated by SEM and TEM. European Polymer Journal, 41, 577-588 (2005). DOI: $10.1016 /$ j.eurpolymj.2004.10.019

[24] Guo B. C., Chen F., Chen W. W., Lei Y. D., Jia D. M.: Reinforcement of nitrile rubber by in situ formed zinc disorbate. Express Polymer Letters, 4, 529-538 (2010). DOI: 10.3144 /expresspolymlett.2010.67

[25] Flory P. J., Krigbaum W. R.: Statistical mechanics of dilute polymer solutions II. Journal of Chemical Physics, 18, 1086-1094 (1950). DOI: $10.1063 / 1.1747866$ 
[26] Gao G., Zhang Z., Zheng Y., Jin Z.: Effect of magnesium methacrylate and zinc methacrylate on bond properties of thermal insulation material based on NBR/ EPDM blends. Journal of Applied Polymer Science, 113, 3901-3909 (2009).

DOI: 10.1002/app.30415

[27] Lu Y., Liu L., Shen D., Yang C., Zhang L.: Infrared study on in situ polymerization of zinc dimethacrylate in poly ( $\alpha$-octylene-co-ethylene) elastomer. Polymer International, 53, 802-808 (2004). DOI: $10.1002 /$ pi.1462

[28] Saito Y., Nishimura K., Asada M., Toyoda A.: Polymerization behavior of zinc methacrylate study of zinc methacrylate/rubber/peroxide compounds; Part 2 (in Japanese). Japanese Rubber Society, 67, 867-872 (1994).

[29] Peng Z., Liang X., Zhang Y., Zhang Y.: Reinforcement of EPDM by in situ prepared zinc dimethacrylate. Journal of Applied Polymer Science, 84, 1339-1345 (2002).

DOI: 10.1002/app.10112
[30] Nie Y., Huang G., Qu L., Zhang P., Weng G., Wu J.: Cure kinetics and morphology of natural rubber reinforced by the in situ polymerization of zinc dimethacrylate. Journal of Applied Polymer Science, 115, 99-106 (2010)

DOI: $10.1002 / a p p .31045$

[31] Wei Z., Lu Y., Yan S., Meng Y., Zhang L.: Dramatic influence of curing temperature on micro-nano structure transform of HNBR filled with zinc dimethacrylate. Journal of Applied Polymer Science, 124, 288295 (2012).

DOI: $10.1002 /$ app.34615

[32] Ikeda T., Yamada B., Tsuji M., Sakurai S.: In situ copolymerization behaviour of zinc dimethacrylate and 2-( $N$-ethylperfluoro-octanesulphonamido)ethyl acrylate in hydrogenated nitrile-butadiene rubber during peroxide crosslinking. Polymer International, 48, 446-454 (1999).

DOI: $10.1002 /(\mathrm{SICI}) 1097-0126(199906) 48: 6<446:$ : AID-PI159>3.0.CO;2-9 